Article

\title{
Encapsulation of Grapefruit Essential Oil in Emulsion-Based Edible Film Prepared by Plum (Pruni Domesticae Semen) Seed Protein Isolate and Gum Acacia Conjugates
}

\author{
Chen $\mathrm{Li}^{1}{ }^{1}$, Jiliu Pei ${ }^{1}$, Xiaohui Xiong ${ }^{1, *}$ and Feng Xue ${ }^{2}$ \\ 1 College of Food Science and Light Industry, Nanjing Tech University, 30 Puzhu South Road, Pukou District, \\ Nanjing 211816, China; lichenfs@njtech.edu.cn (C.L.); jiliupei@njtech.edu.cn (J.P.) \\ 2 School of Pharmacy, Nanjing University of Chinese Medicine, Nanjing 210023, China; xuefeng@njucm.edu.cn \\ * Correspondence: sateam@njtech.edu.cn; Tel.: +86-138-13362715
}

Received: 14 July 2020; Accepted: 8 August 2020; Published: 12 August 2020

\begin{abstract}
A dry-heated Maillard reaction was used to prepare plum seed protein isolate and gum acacia conjugates. Emulsion-based edible films (EBEF) were prepared by the encapsulation of grapefruit essential oil using conjugates solution as the continuous phase. The conjugates formed from 3 days of dry heating showed a significant improvement in emulsifying properties due to the unfolding of protein, as confirmed by structure analysis. The droplet size, electrical charge, and viscosity of emulsions increased with the increasing essential oil concentration, and all emulsions exhibited 'gel'-like behavior. The water vapor barrier property, surface hydrophobicity, mechanical properties, and thermal stability of the films were improved as the essential oil content increased in the range of $1-4 \%$ due to enhancement in intermolecular interaction and compatibility, as well as a denser microstructure. Furthermore, all films exhibited an inhibitory effect against $E$. coli, while their radical scavenging activity depended on the release rate from films. The results obtained in this work confirmed that EBEF could be used as a novel food active packaging in the near future.
\end{abstract}

Keywords: Maillard conjugates; emulsion based edible films; grapefruit essential oil

\section{Introduction}

Proteins, polysaccharides, and lipids are the main components used to produce edible films. However, there are some disadvantages for each polymer. Protein films, such as soy protein, corn protein, whey protein, and caseinates, possessed better barrier properties but poorer mechanical properties than polysaccharides films [1,2]. The films made from polysaccharides (such as chitosan, fiber, and starch) were more transparent and oil-resistant but exhibited higher water permeabilities than protein films. The lipids films, such as beeswax and fatty acids, were fragile and brittle, but were used for water transmission reduction [3]. Therefore, it is important to produce hybrid films by combining hydrophilic matrix with hydrophobic compounds in order to obtain multiple properties.

The composite films from hydrocolloids and lipids mixtures can be obtained by bilayers or emulsions technology. The bi-layers films have shown some cracks or non-uniform surface [4]. Therefore, the emulsion-based edible films (EBEF), which can be easily obtained by film-forming casting following drying process, have attracted increasing research interest [5]. The properties of EBEF can be significantly affected by emulsification techniques, as well as the type and quantities of hydrocolloids or lipids and their compatibility [6]. Therefore, the emulsifying properties of hydrocolloids are important to properties of films. 
Protein and polysaccharide conjugates can be produced by Maillard-type reactions. It has been reported that conjugates prepared from this method exhibited remarkable emulsifying properties [7]. Our previous studies have also suggested that grafted soy protein, peanut protein, and buckwheat protein showed significant improvement in emulsifying properties [8-12]. Moreover, our previous study found that grafted peanut protein showed superior film-forming abilities [13]. Therefore, the grafted protein could be a potential material for the preparation of EBEF.

Plum (Pruni domesticae semen) is a multi-purpose crop of great industrial importance, which is widely cultivated in China. Plum seed, due to its high content in amygdalin $\left(20 \mathrm{~g} \mathrm{~kg}^{-1}\right)$ and protein (typically over $280 \mathrm{~g} \mathrm{~kg}^{-1}$ ), became a valuable source of Chinese medicine and food [14]. Usually, the seed was only used for extraction of amygdalin for its anti-tumor activity, resulting in abundant protein waste. Therefore, it is necessary to employ a technique, such as graft modification, in order to utilize this protein preferably.

The essential oil (EO) has shown many biological activities, such as antioxidant, antimicrobial, and insecticidal properties [15]. For this reason, incorporation of EO into edible films as food active packaging is preferred in food industry. It was reported that EO from grapefruit exhibited antibacterial and antifungal effects [16]. Edible films incorporated with citrus oil have also been reported to be able to enhance the overall quality of fruits and vegetables. Therefore, grapefruit essential oil could serve as a potential active compound in food active packaging to inhibit the growth of spoilage and protect food against oxidation [17].

Gum acacia (GA) is a well-characterized and favorable polysaccharide, which is utilized as a thickener, emulsifier, and film-forming agent in the food industry $[9,18,19]$. In this study, for the first time, new plum seed protein isolate (PSPI) conjugates were prepared with gum acacia through Maillard reaction, and the conjugates were applied to prepare EBEF. The emulsion behavior prepared by PSPI-GA conjugates and grapefruit essential oil (GF-EO) was characterized; the physical, structural, antioxidant, and antimicrobial properties as well as the release patterns of essential oil from PSPI-GA emulsion-based films were also evaluated.

\section{Results and Discussion}

\subsection{Physicochemical Properties of Conjugates}

The contents of lysine and arginine were lower in PSPI-GA conjugates (PSPI-GA 1, PSPI-GA 3, PSPI-GA 5) compared to the PSPI and GA mixtures (PSPI-GA) Figure 1A), which is consistent with previous study that showed that lysine and arginine are main free amino groups taking part in the Maillard reaction [9]. The results indicated that the conjugates were formed by covalent binding.

As shown in Figure 1B,C, both EAI and ESI of conjugates increased as the conjugation reaction continued up to 3 days, while decreased afterwards. This increase is attributed to the conjugates combining the emulsifying property of proteins with the solvation property of the polysaccharides [20]. The decrease might be due to the generation of polymerization products as Maillard reaction proceeded [18].

As suggested in Figure 1D, $\mathrm{H}_{0}$ values of conjugates were significantly $(p<0.05)$ lower than that of PSPI/GA mixtures. As shown in Figure 1E, $\lambda$ max was shifted to longer wavelengths (bathochromic shift) when PSPI was grafted with GA, indicating the changes of PSPI conformation. As shown in Figure $1 \mathrm{~F}$, conjugates exhibited an increase of unordered coils. These changes in structure all suggested that the attachment of GA to PSPI lead to more hydrophilic and disordered structures with greater conformational flexibility. 

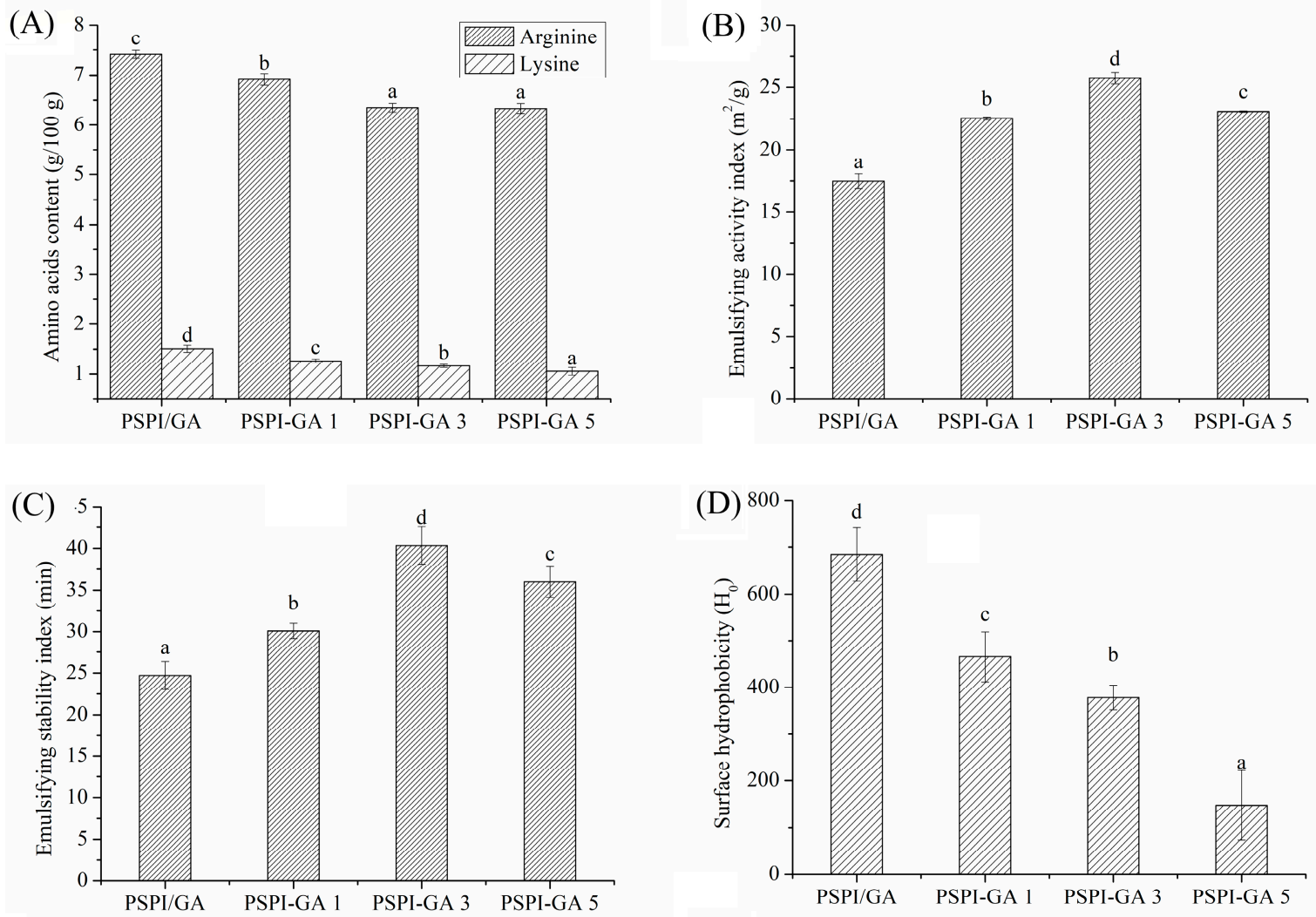

(E)
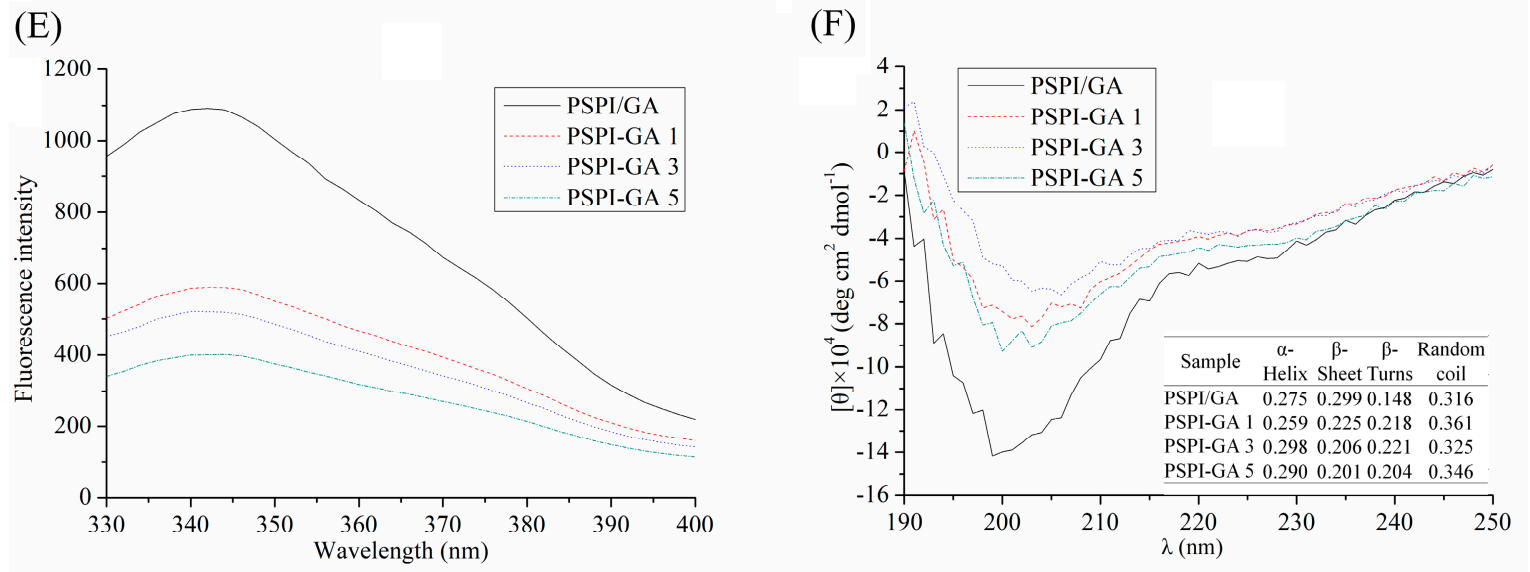

Figure 1. Lysine and arginine content (A), emulsifying properties (B) and (C) and surface hydrophobicity (D), intrinsic emission fluorescence (E) and circular dichroism spectrum (F) of conjugates. PSPI/GA: mixture of plum seed protein isolate (PSPI) and gum acacia (GA); PSPI-GA 1/3/5: the PSPI-GA conjugates prepared from 1, 3, or 5 days. PSPI: plum seed protein isolates. GA: gum acacia. Different letters in the same pattern represent significant difference $(p<0.05)$.

\subsection{Film-Forming Emulsion Properties}

\subsubsection{Size Distribution}

Considering the negative effects of extended dry heating on emulsifying properties, the conjugates prepared from 3-day reactions were chosen for preparing the film-forming emulsion. The size distribution of film-forming emulsion containing different contents of EO was analyzed. Only one peak was observed in Figure 2A, indicating that the incorporation of EO into the emulsion of conjugates resulted in a mono-modal distribution of droplets. This result is consistent with soy protein films containing cinnamon and ginger EO previously reported [21]. In contrast, researchers observed a multimodal distribution of droplets, when cinnamon or ginger EO was incorporated in 
sodium caseinate-based films [22]. Multimodal distribution was also reported in soy protein-based film emulsified with flaxseed oil [23], gelatin-based films emulsified with olive oil [24], and whey protein-based films emulsified with rapeseed oil [25]. They attributed this phenomenon to the aggregation of polymers and coalescence of smaller droplets into larger ones after emulsification. In addition, Volume-mean diameter (D [3,4]) values of emulsion with EO concentrations ranging from $1 \%$ to $6 \%$ were $33.02 \pm 2.01,34.17 \pm 1.94,40.90 \pm 3.04$, and $63.84 \pm 7.78 \mu \mathrm{m}$, respectively, indicating that the droplet diameter of film-forming emulsion increased as the EO concentration increased. This result might be due to the fact that with the increasing of EO concentration, insufficient adsorption of conjugates at the oil-water interface might occur, leading to flocculation and coalescence after emulsification. On the other hand, the increasing of EO concentration could also resulted in thinner interfacial film surrounding the oil droplets, which is more susceptible to rupturing.
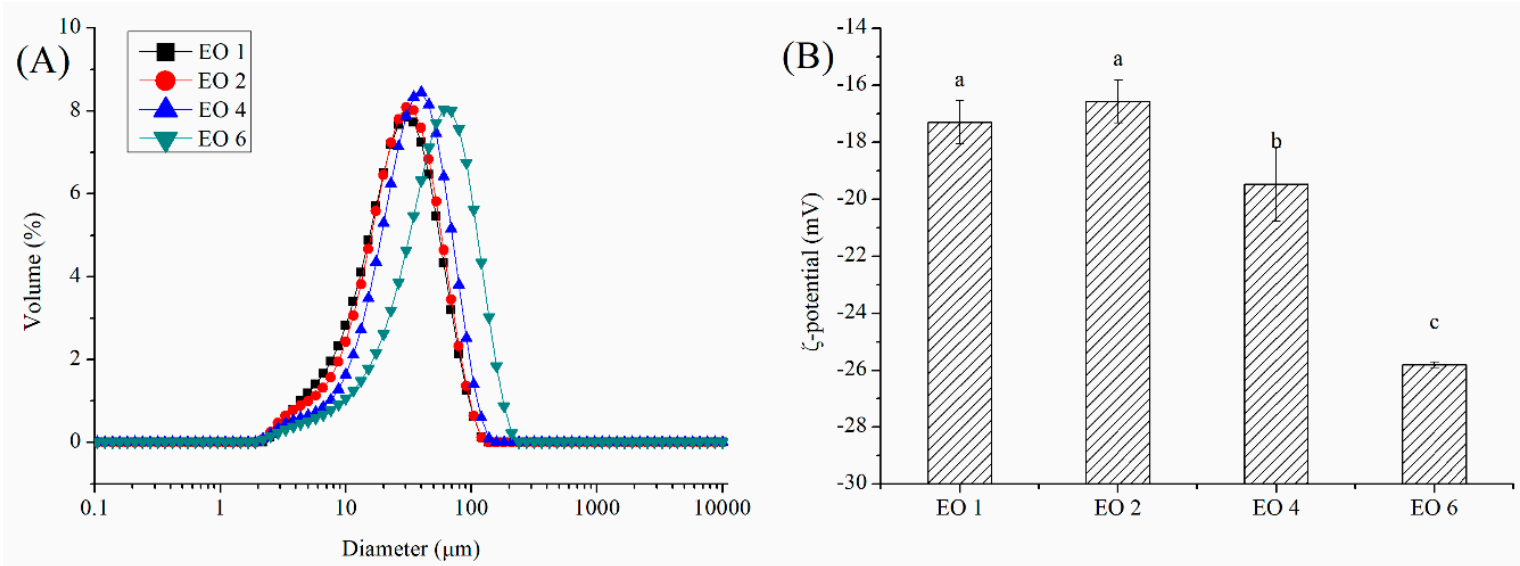

Figure 2. Droplet size distributions (A) and $\zeta$-potential (B) of film-forming emulsion. EO 1/2/4/6: PSPI-GA conjugates emulsions containing grapefruit essential oil at $1 \% / 2 \% / 4 \% / 6 \%$ level. PSPI: plum seed protein isolates. GA: gum acacia. EO: grapefruit essential oil. Different letters in the same pattern represent significant difference $(p<0.05)$.

\subsection{2. ¿-Potential}

It is well known that the electrical charge of oil droplets is important in the stability of emulsion by affecting the electrostatic repulsion. As suggested in Figure 2B, due to the anionic nature of PSPI-GA conjugates absorbed to oil droplets, the negative electrical charge was observed in all emulsions. EO concentration significantly affect the electrical charge. This is probably attributed to the ionizable compounds presented in EO. Furthermore, the difference of $\zeta$-potential might lead to the changing of the intermolecular electrical repulsion in films, which could result in the changing of film structures.

\subsubsection{Rheological Behavior}

The viscosity of the film-forming solution are important to film properties, which could affect the removal of air bubbles [26] and elimination of sagging [27] during the process. Therefore, the flow curves of film-forming emulsion loaded with different concentrations of $\mathrm{EO}$ were analyzed. As shown in Figure 3A, the viscosity of emulsion increased as the EO concentration increased, which is probably due to the high viscosity of oil. In general, the film-forming emulsion showed shear thinning behavior. The $\mathrm{R}^{2}$ (coefficient of determination) values for emulsion with $\mathrm{EO}$ concentration ranging from $1 \%$ to $6 \%$ were $0.7331,0.6891,0.9456$ and 0.9262 , respectively. These results indicated that the fitted curves for the emulsions with a higher concentration of EO gave good agreement with the experimental data and that the degree of shear thinning increased as the concentration increased. The flow behavior index of emulsion with $\mathrm{EO}$ concentration ranging from $1 \%$ to $6 \%$ was calculated as $0.677,0.629,0.476$, and 0.412 , respectively. These results indicated that all the film-forming emulsions exhibited a pseudo plastic behavior (the flow behavior index $<1$ ) in which the viscosity decreases with the increasing of shear rate. This behavior is 
attributed to the fact that interactions between the emulsion components were disrupted as the shear rates increased [23]. Previous studies reported a similar result in which that shear thinning behavior for emulsion was observed when flaxseed oil was emulsified into soy protein films at concentrations ranging from $3 \%$ to $10 \%$ [23]. The consistency coefficient of emulsion with EO concentration ranging from $1 \%$ to $6 \%$ was calculated as $0.0093,0.0158,0.0352$ and $0.0798 \mathrm{~Pa} \mathrm{~s}^{\mathrm{n}}$, respectively. The value of the consistency coefficient is related to the inter-molecular forces of emulsion according to previous study [28]. Thus, the inter-molecular forces in emulsion increased as the EO concentration increased.
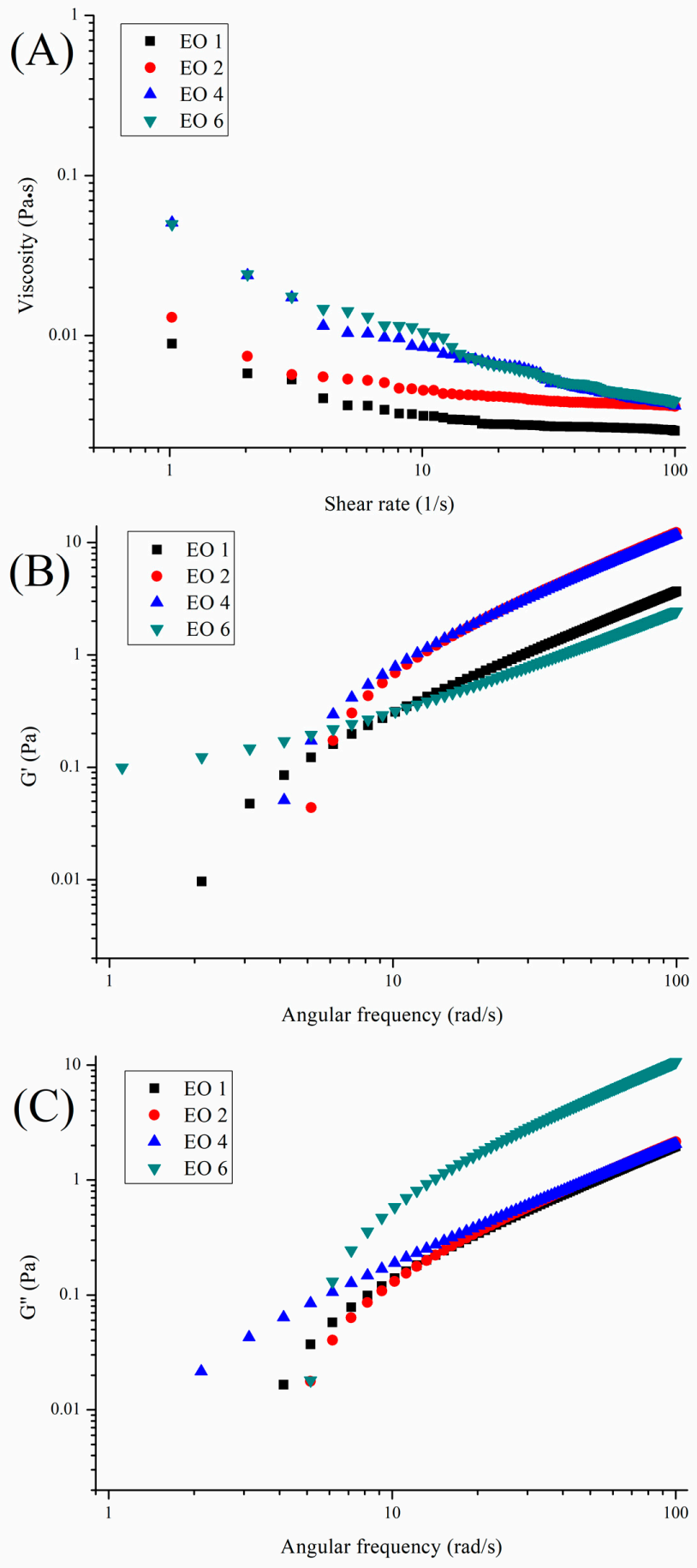

Figure 3. Flow curves (A), storage modulus (B), and loss modulus (C) of film-forming emulsion. EO 1/2/4/6: PSPI-GA conjugates emulsions containing grapefruit essential oil at $1 \% / 2 \% / 4 \% / 6 \%$ level. PSPI: plum seed protein isolates. GA: gum acacia. EO: grapefruit essential oil. 
Figure $3 B, C$ shows the influence of EO concentration on the variation of the storage modulus $\left(G^{\prime}\right)$ and loss modulus $\left(G^{\prime}\right)$ of film-forming emulsion. It could be observed that the value of $G^{\prime}$ is higher that $G$ " for all samples. These results indicated that all samples exhibited 'gel'-like behavior along the entire frequency range. The concentration of EO significantly affected the values of $G^{\prime}$ and $G^{\prime \prime}$ of the film-forming emulsion. The possible reason for this phenomenon is that the concentration of EO could change the particle size distribution, which has been proven to have dramatic effects on flow properties [29]. On the other hand, the concentration of EO could also change the inter-molecular forces, which have been proven to affect the formation of the gel network [30].

\subsection{Film Physical Properties}

\subsubsection{Transparency, Whiteness Index, and Swelling Ability}

As shown in Table 1, the transparency of films was significantly affected by EO concentration. The values decreased as EO concentration increased from $1 \%$ to $4 \%$, followed by an increase at the $6 \%$ EO level. On one hand, the transparency of emulsion-based films is affected by the oil type and concentration due to the fact that oil could change the extent of light scattering. On the other, the film surface and internal structure could also affect the light reflection and absorption. Therefore, the effects of oil concentration on the microstructure of films were studied later.

Table 1. Transparency, whiteness index, swelling, water vapor permeability (WVP), contact angle, tensile strength (TS), elongation at break (EB), and appearance of PSPI-GA films made from essential oil emulsions.

\begin{tabular}{|c|c|c|c|c|c|c|c|c|}
\hline Sample & $\begin{array}{l}\text { Transparency } \\
(\% / \mathbf{m m})\end{array}$ & $\begin{array}{l}\text { Whiteness } \\
\text { Index WI }\end{array}$ & Swelling (\%) & $\begin{array}{c}\text { WVP } \\
\mathrm{mg} /\left(\mathrm{cm}^{2} \cdot \mathrm{d}\right)\end{array}$ & $\begin{array}{c}\text { Contact } \\
\left.\text { Angle ( }{ }^{\circ}\right)\end{array}$ & TS (MPa) & EB (\%) & Appearance \\
\hline EO 1 & $1.36 \pm 0.06^{\mathrm{d}}$ & $69.99 \pm 0.68^{d}$ & $599.57 \pm 15.07^{\mathrm{d}}$ & $90.98 \pm 1.80^{c}$ & $104.94 \pm 1.20^{\mathrm{a}}$ & $1.88 \pm 0.09^{b}$ & $26.55 \pm 4.02^{\mathrm{a}}$ & \\
\hline $\mathrm{EO} 2$ & $0.85 \pm 0.01^{\mathrm{c}}$ & $64.34 \pm 0.42^{c}$ & $567.75 \pm 11.07^{c}$ & $87.22 \pm 1.06^{b}$ & $108.14 \pm 0.81^{b}$ & $2.78 \pm 0.17^{c}$ & $30.43 \pm 2.99^{a}$ & \\
\hline $\mathrm{EO} 4$ & $0.71 \pm 0.02^{\mathrm{a}}$ & $59.47 \pm 0.44^{b}$ & $466.51 \pm 42.21^{b}$ & $78.95 \pm 2.22^{\mathrm{a}}$ & $114.96 \pm 2.01^{c}$ & $3.45 \pm 0.24^{\mathrm{d}}$ & $45.30 \pm 1 \mathrm{ss} .76^{\mathrm{c}}$ & \\
\hline EO 6 & $0.78 \pm 0.01^{b}$ & $56.52 \pm 0.64^{a}$ & $388.77 \pm 30.47^{\mathrm{a}}$ & $80.22 \pm 1.83^{a}$ & $110.85 \pm 3.11^{b c}$ & $1.54 \pm 0.11^{\mathrm{a}}$ & $39.40 \pm 2.21^{\mathrm{b}}$ & \\
\hline
\end{tabular}

EO 1/2/4/6: PSPI-GA conjugate films containing grapefruit essential oil at $1 \% / 2 \% / 4 \% / 6 \%$ level. PSPI: plum seed protein isolates. GA: gum acacia. EO: grapefruit essential oil. Different letters within a column represent significant difference $(p<0.05)$.

As shown in Table 1, the concentration of EO had a significant effect on the whiteness index of films. Overall, films became darker as the EO concentration increased. The increase in darkness is presumably due to the existence of EO, which contains pigments and is orange in color. The result is consistent with the visual appearance in films (Table 1). Changes in whiteness index affected by the color of the oil added were also observed in previous study in which the lightness of a soy protein-based emulsion-type film decreased as the flaxseed oil concentration increased [23].

As suggested in Table 1, swelling ability of the films decreased along with the increase of EO concentration. The decrease in swelling ability is thought to be associated with an increasing of hydrophobicity by adding EO, which could prevent the matrix from binding strongly to water and thus reduce water uptake. Our result is consistent with previous researches that showed that the swelling ability of chitosan-based films decreased as the virgin coconut oil concentration increased [31] and similar to results observed in soy protein film with flaxseed oil [23].

\subsubsection{Water Vapor Permeability (WVP), Contact Angle, and Mechanical Properties}

The water vapor permeability is directly related to the property of the film to restrict water migration of the food. The most striking feature for EBEF is the excellent water vapor barrier property, which might be attributed to the oil incorporation. As shown in Table 1, the WVP decreased as the 
EO concentration increased from $1 \%$ to $4 \%$. This is probable due to the fact that the viscosity of film-forming emulsion increased as EO levels increased. It has been proven that increasing the viscosity of film-forming emulsion could reduce water mobility through the film [23]. However, the WVP was not decreased as EO levels increased to $6 \%$. This is probably due to the disruption of structure which might provide channels for water migration.

Water contact angle are important in the film surface wettability and moisture transport. Higher surface hydrophobicity is necessary for EBEF when used as packaging or coatings; hence, the contact angle of edible films should be as large as possible. As suggested in Table 1, films made of EO at the $4 \%$ level possessed the highest contact angle. This is helpful for explaining why this film showed the lowest water vapor permeability.

Mechanical properties, which are usually measured by tensile strength (TS) and elongation at break (EB), are key factors that determined the industrial application of films. In theory, the incorporation of oil would disrupt the biopolymer network in the film, leading to increased flexibility (EB) and decreased TS [32]. For instance, the incorporation of beeswax into pea-starch films decreased the tensile strength when lipids became greater than $20 \%$ [33]; incorporation of olive oil decreased the tensile strength of a gelatin-based film when the oil-to-protein ratio was increased from $5 \%$ to $10 \%$ [24]; the incorporation of sunflower oil decreased the tensile strength of quinoa protein-chitosan based films when the lipids concentration was increased from $2.9 \%$ to $34.7 \%$ [34]. In contrast (as shown in Table 1), the tensile strength of films increased as the EO concentration increased in the range of $1-4 \%$. This trend has been observed in previous studies in which the incorporation of flaxseed oil into soy protein-based films increased the tensile strength when the lipids concentration was increased from $1 \%$ to $5 \%$ [23]. Ataréz et al. also reported that the increasing of cinnamon oil content resulted in an increase in the tensile strength of soy protein-based films [21]. They attribute this phenomenon into protein rearrangement, which resulted in a more ordered structure. The tensile strength decreased as the EO content increased to $6 \%$, which is probably due to disruption of the biopolymer network and the formation of a holey microstructure. As expected in Table 1, the elongation of films was found to be increased significantly when the EO content increased from $1 \%$ to $4 \%$, and then it decreased with the further increasing of EO content. The increasing of elongation was due to the increase in electrical charge of film-forming emulsion and droplet sizes. It has been proven that repulsive forces among molecules can increase the distance between polymers and that larger droplet sizes could decrease chain-chain interactions, which resulted in a plasticizing effect [28]. In fact, the mechanical properties of films are possibly dependent upon a variety of parameters, such as the type of ingredient, oil content, properties of film-formation emulsion, microstructure of films, and so on. In this study, it is possible that $6 \%$ EO concentration might result in a discontinuous microstructure to give lower elongation. This is probably due to the EO migration upwards in the films and further volatilization during water evaporation, leading to a holey structure.

\subsection{Thermal Properties of Films}

Differential scanning calorimetry (DSC) technology is generally employed to evaluate the thermal transition of edible films. As shown in Figure 4A, endothermic peaks appeared in the range of $180-200{ }^{\circ} \mathrm{C}$, which can be attributed to the melting temperature (Tm) of films. The films with $2 \%$ or $4 \%$ EO have one endothermic peak, indicating good compatibility between the film components. Multiple peaks were observed as the EO concentration increased to $6 \%$. All those results indicated that the concentration of EO could affect the interactions between polymers, which could result in changes of the Tm [35]. On the other hand, the appearance of a new peak suggested that a Maillard reaction occurred during the film-forming process [36]. 

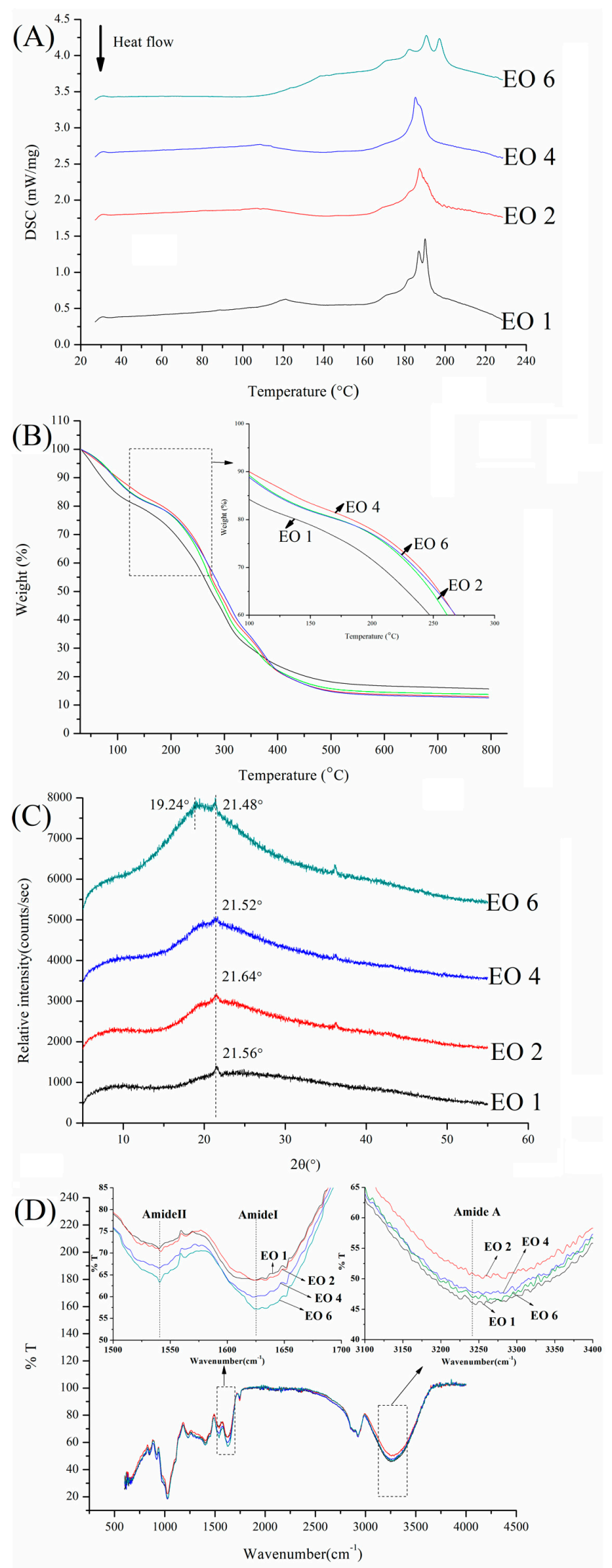

Figure 4. Differential scanning calorimetry (DSC) curves (A), Thermal gravimetric (TG) thermograms (B), X-ray diffraction patterns (C) and Fourier Transform Infrared (FTIR) spectra (D) of PSPI-GA films containing essential oil. EO 1/2/4/6: PSPI-GA conjugates films containing grapefruit essential oil at $1 \% / 2 \% / 4 \% / 6 \%$ level. PSPI: plum seed protein isolates. GA: gum acacia. EO: grapefruit essential oil. 
TG curves are widely applied to study the thermal decomposition of films as reflected by their weight loss under continuous heating conditions. The higher onset decomposition temperatures of films indicated the better thermal stability [37]. As shown in Figure 4B, the thermal stability of films was significantly improved as the EO content increased in the range of $1-4 \%$; then, it decreased with the further increasing of EO concentration.

\subsection{X-Ray Diffractometry}

XRD was widely applied to study the compatibility of components in the films. As shown in Figure $4 \mathrm{C}$, a single peak located around $2 \theta=21^{\circ}$ was observed in films with $1 \%-4 \% \mathrm{EO}$, indicating that the components in the films were in an amorphous state. The peak became broader as the EO concentration increased from $1 \%$ to $4 \%$, suggesting the good compatibility between the EO and polymers in the films. A strong peak located around $2 \theta=19^{\circ}$ appeared as the EO content increased to $6 \%$, indicating the formation of new crystalline domains. This result supported the appearance of multiple peaks in DSC analyses.

\subsection{Fourier Transform Infrared Spectroscopy (FTIR)}

FTIR was employed to analyze the functional groups in EBEF to evaluate the effect of EO on the interactions between polymers. The absorption band of amide-A was commonly used to study the hydrogen bonds, due to $\mathrm{N}-\mathrm{H}$ and $\mathrm{O}-\mathrm{H}$ bands participate in the formation of hydrogen bonds [38]. As shown in Figure 4D, the band intensity of amide-A was affected by the content of EO, which indicated that the concentration of EO could affect the hydrogen bonds' interaction between the polymers. In addition, amide-I and amide-II are common parameters for studying Maillard reaction $(\mathrm{C}=\mathrm{N}$ stretching vibration) between proteins and polysaccharides [35]. As suggested by Figure $4 \mathrm{D}$, the band intensity of amide-I and amide-II increased with the increasing of EO concentration, which suggested that the concentration of EO could affect the Maillard reaction during the film-forming process and then change the physicochemical properties of films.

\subsection{Microstructure}

The surface (S) and cross-section (C) of films are shown in Figure 5. Generally, films containing EO showed a rough surface. This result is consistent with previous researches that incorporation of EO led to the increase of coarseness on film surfaces $[28,39]$. They attributed this result to the oil droplets migration and volatilization upwards the films, leading to an irregular surface. Moreover, both the surface and cross-section became denser and more compact as the EO content increased from $1 \%$ to $4 \%$, which could help understand the improvement in TS and thermal stability. However, the holey surface in the cross-section was observed as the EO concentration increased to $6 \%$. The appearance of a holey microstructure might help us understand why the film with $6 \%$ EO showed a decrease in transparency, TS, EB, and thermal stability. 


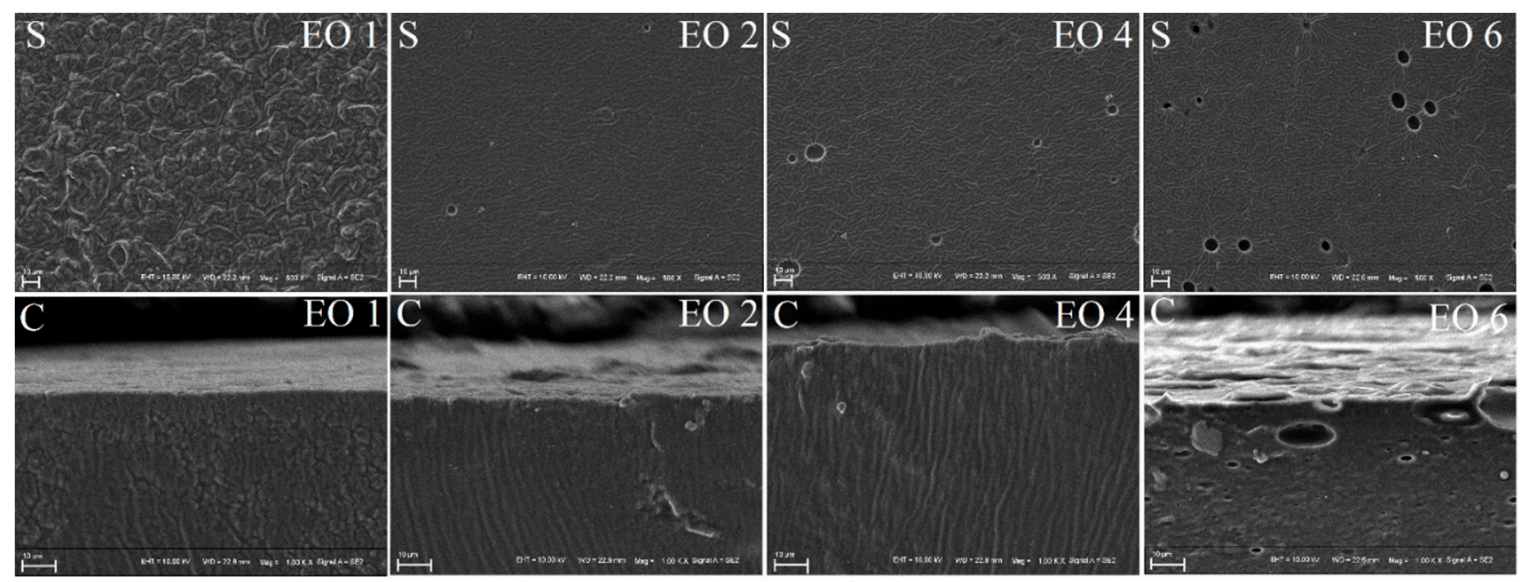

Figure 5. SEM images of the surface (S) and cross-section (C) of PSPI-GA films containing essential oil. EO 1/2/4/6: PSPI-GA conjugates films containing grapefruit essential oil at $1 \% / 2 \% / 4 \% / 6 \%$ level. PSPI: plum seed protein isolates. GA: gum acacia. EO: grapefruit essential oil.

\subsection{Antioxidant and Antimicrobial Activity}

Grapefruit is regarded as highly nutritional because of the presence of various phytonutrients, such as vitamins, terpenes, and other compounds. The essential oil from grapefruit was reported to possess antibacterial and antifungal effects [16]. A previous report suggested that films emulsified with cinnamon essential oil could exhibit antioxidant activity, which increasing as the essential oil content increased [40]. However, in our study, all films with EO exhibited radical scavenging activity but the film with $1 \%$ EO showed the best of antioxidant activity (Figure $6 \mathrm{~A}$ ). In fact, the antioxidant activity of film is related to the EO concentration released from film. Therefore, the release kinetics of EO from PSPI-GA films was also investigated in this study. Furthermore, all films containing EO demonstrated antimicrobial effect against $E$. coli (as shown in Figure 6B, and it was not significantly affected by EO concentration $(p<0.05)$ ). The result is consistent with previous studies, in which essential oil incorporated in polysaccharides films showed antimicrobial behavior against $E$. coli due to the destruction of the bacteria cell membrane [41,42]. 

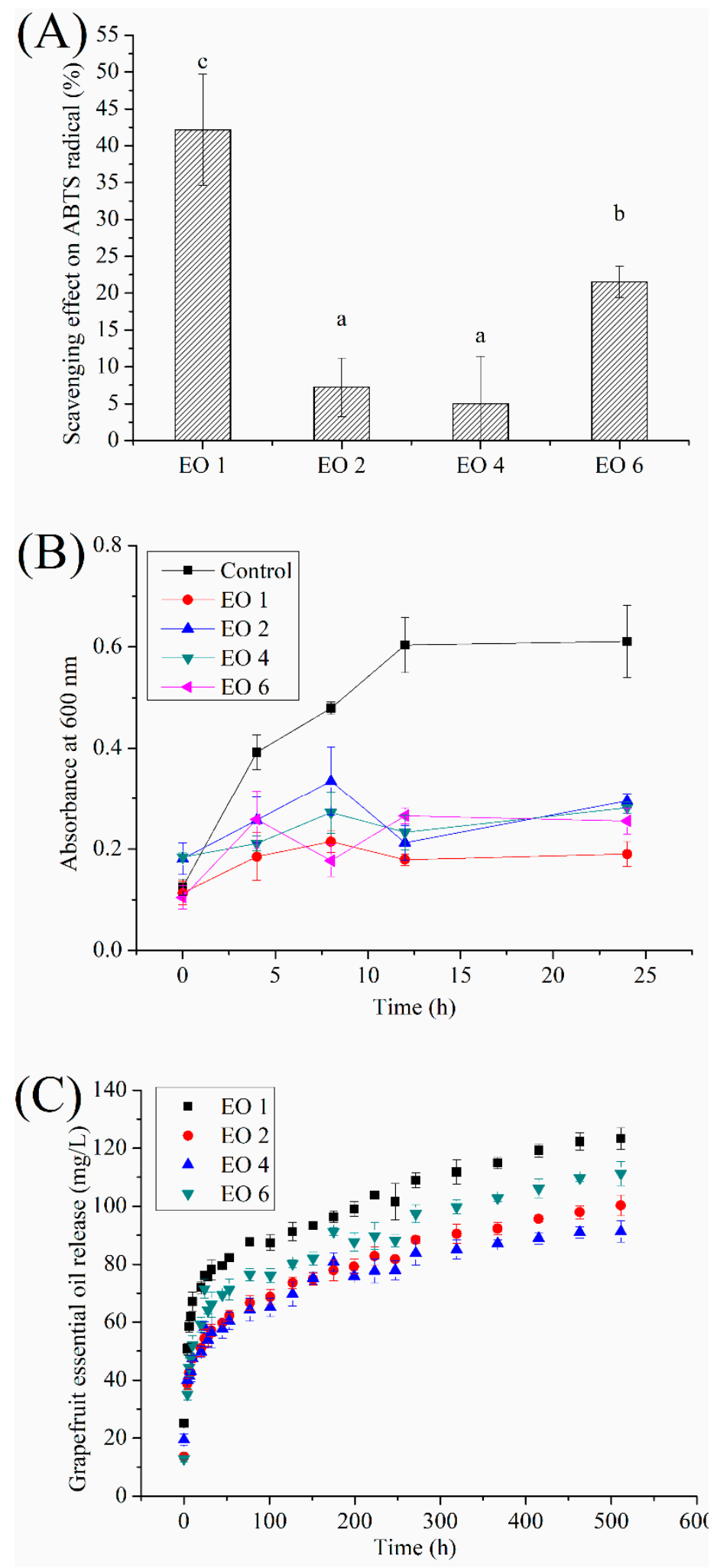

Figure 6. Antioxidant (A), antimicrobial (B) activity, and oil release kinetics (C) of PSPI-GA films containing essential oil. EO 1/2/4/6: PSPI-GA conjugates films containing grapefruit essential oil at $1 \% / 2 \% / 4 \% / 6 \%$ level. PSPI: plum seed protein isolates. GA: gum acacia. EO: grapefruit essential oil. Different letters in the same pattern represent significant difference $(p<0.05)$. 


\subsection{Release Kinetics of EO from Films}

It can be observed from Figure 6C that the release kinetics of EO from PSPI-GA films followed a typical exponential pattern. This result is consistent with previous study of the release behavior of lemongrass oil from alginate film [43]. As suggested in Table 2, the release data of EO fitted better to the Peppas model ( $\mathrm{r}^{2}$ close to 1$)$ than the Weibull model. In general, the $\mathrm{n}$ constant of the Peppas model took values lower than 0.5 , indicating that the release mechanism is a combination of partial diffusion through a swollen matrix and pores filled with water [44]. Interestingly, the levels of essential oil released from films decreased as the EO content increased in the range of $1-4 \%$. This is probably due to the formation of a more ordered structure as supported by TS and microstructure analysis. The released level increased as the EO content increased to $6 \%$. This is probably due to the formation of a holey structure, which might benefit the release of EO from films. In addition, released levels are positively related to their antioxidant activity.

Table 2. Kinetics parameters obtained from release curves of films containing essential oil.

\begin{tabular}{cccc}
\hline \multirow{2}{*}{ Sample } & \multicolumn{3}{c}{ Peppas Model } \\
\cline { 2 - 4 } & Regression Coefficient $\left(\mathbf{r}^{\mathbf{2}}\right)$ & $\mathbf{K p}$ & $\mathbf{n}$ \\
\hline EO 1 & 0.9771 & 0.3230 & 0.1643 \\
EO 2 & 0.9928 & 0.2581 & 0.1986 \\
EO 4 & 0.9835 & 0.2753 & 0.1777 \\
EO 6 & 0.9671 & 0.2689 & 0.1938 \\
\hline \multirow{2}{*}{ Sample } & \multicolumn{3}{c}{ Weibull Model } \\
& Regression Coefficient $\left(\mathbf{r}^{\mathbf{2}}\right)$ & $\mathbf{a}$ & $\mathbf{b}$ \\
\hline EO 1 & 0.9352 & 0.3100 & 0.3027 \\
EO 2 & 0.9589 & 0.2384 & 0.3347 \\
EO 4 & 0.9696 & 0.2721 & 0.2878 \\
EO 6 & 0.9504 & 0.2340 & 0.3455 \\
\hline
\end{tabular}

EO 1/2/4/6: PSPI-GA conjugates films containing grapefruit essential oil at $1 \% / 2 \% / 4 \% / 6 \%$ level. PSPI: plum seed protein isolates. GA: gum acacia. EO: grapefruit essential oil.

\section{Materials and Methods}

\subsection{Materials and Chemicals}

The plum seed flour was provided by a local supplier in Nanjing (China); grapefruit essential oil (main constituents provided in Supplementary Materials); 2,2'-Azino-bis (3-ethylbenzo-thiazoline6-sulfonic acid) diammonium salt (ABTS) radical; strain of Escherichia coli (CMCC 44102) were purchased from Shanghai Yuanye biotechnology Co., Ltd. (Shanghai, China). The glycerol was obtained from Macklin Biochemical Co., Ltd. (Shanghai, China). Gum acacia (GA) and other reagents were obtained from Sinopharm Chemical Reagent Co., Ltd. (Shanghai, China).

\subsection{Analysis of Grapefruit Essential Oil}

Solid-phase microextraction (SPME) coupled with gas chromatography mass spectrometry (GC-MS) was used to analyze main components in grapefruit essential oil. The volatiles were extracted using a 50/30 $\mu \mathrm{m}$ Divinylbenzene/Carboxen/Polydimethylsiloxane (DVB/CAR/PDMS) fiber (Supelco, Bellefonte, PA, USA). The essential oil $(10 \mathrm{~mL})$ was placed in a $20 \mathrm{~mL}$ vial, and extracted by the fiber at $40{ }^{\circ} \mathrm{C}$ for $30 \mathrm{~min}$. After extraction, the fiber was thermally desorbed in the GC injection port for $5 \mathrm{~min}$.

The analysis was performed by An Agilent 7890 B GC coupled with an Agilent 7000 mass spectrometer (Agilent, Santa Clara, CA, USA), equipped with an HP-5MS fused silica capillary column (30 m length, $0.25 \mathrm{~mm}$ inner diameter, $0.25 \mu \mathrm{m}$ film thickness; Agilent). The mass spectrometer ion source temperature was at $230^{\circ} \mathrm{C}$, the electron energy was at $-70 \mathrm{eV}$. The oven temperature was first raised 
from 60 to $210^{\circ} \mathrm{C}$ at $3{ }^{\circ} \mathrm{C} / \mathrm{min}$, then raised to $240{ }^{\circ} \mathrm{C}$ at $20^{\circ} \mathrm{C} / \mathrm{min}$, and held for $8 \mathrm{~min}$. The compounds were identified by comparing the mass spectra with those contained in the database (NIST11).

\subsection{Preparation of Plum Seed Protein Isolates (PSPI)—Gum Acacia (GA) Conjugates}

The PSPI was prepared using alkali-acid precipitation according to our previous study [45]. Conjugates of PSPI-GA were also prepared according to our previous study [18]. PSPI-GA (1:1 in deionized water, $w / w)$ solutions $(10 \%, w / v)$ were spray-dried. The powders obtained were heated for 1,3 , or 5 days at $60{ }^{\circ} \mathrm{C}$ in the presence of saturated $\mathrm{KBr}$ solution (79\% relative humidity), and then vacuum-dried. The resultant samples were PSPI-GA conjugates (PSPI-GA 1, PSPI-GA 3, and PSPI-GA 5). PSPI-GA powders without dry-heating were used as control (PSPI-GA).

\subsection{Determination of Amino Acids, Emulsifying Properties, Surface Hydrophobicity, and Structure of Conjugates}

The lysine and arginine levels, emulsifying activity index (EAI), emulsifying stability index (ESI), surface hydrophobicity, intrinsic emission fluorescence spectra, and circular dichroism spectrum were measured according to our previous study [9]. The lysine and arginine contents were measured by an Agilent 1100 high performance liquid chromatograph (Agilent technologies Co., Ltd., Santa Clara, CA, USA) equipped with an ODS Hypersil column $(5 \mu \mathrm{m}, 250 \times 4.6 \mathrm{~mm})$. Fluorescence intensity (FI) was determined with a Hitachi F-7000 fluorescence spectrometer (Hitachi, Ltd., Tokyo, Japan) at excitation wavelength of $390 \mathrm{~nm}$ and emission wavelength of $470 \mathrm{~nm}$. The initial slope of the FI versus protein concentration plot was the index of surface hydrophobicity. Intrinsic emission fluorescence spectra of the samples were analyzed by a Hitachi F-7000 fluorescence spectrophotometer (Hitachi, Ltd., Tokyo, Japan). The circular dichroism spectrum of samples was obtained using a Mos-450 CD spectropolarimeter (Biologic, Claix, France).

\subsection{Preparation of Film-Forming Emulsion}

Conjugates ( 3 days incubation) solution $(5 \%, w / v)$ was stirred for at least $12 \mathrm{~h}\left(4{ }^{\circ} \mathrm{C}\right)$, and then added with glycerol $(2 \%, w / v)$, stirring for another $1 \mathrm{~h}$. For coarse emulsion forming, grapefruit essential oil at proportions of $1 \%, 2 \%, 4 \%$, and $6 \%(w / w)$ were incorporated into the dispersion by using the FM200 homogenizer (FLUKO, Shanghai, China) at 10,000 rpm for $2 \mathrm{~min}$. Then, the coarse emulsion was treated with a pressure homogenizer (ATS, Beijing, China) at $70 \mathrm{MPa}$ for 2 passes. The resulted emulsion was then degassed for at least 30 min using vacuum oven.

\subsection{Characterization of Film-Forming Emulsion}

\subsubsection{Particle Size and $\zeta$-Potentials}

The film-forming emulsions were diluted with distilled water $(1 / 20, w / w)$ and stirred for $5 \mathrm{~min}$ at $25{ }^{\circ} \mathrm{C}$. The particle sizes of samples were measured by light scattering using a Mastersizer 2000 equipped with a Hydro $2000 \mathrm{MU}$ dispersion unit from Malvern Instruments Ltd. (Worcestershire, UK). The pump speed was settled at $1800 \mathrm{rpm}$, and the refractive index and absorption parameter were 1.330 and 0.001 , respectively. The $\zeta$-potential of film-forming solutions was measured using a nanoZS instrument (Malvern Instruments, Worcestershire, UK).

\subsubsection{Rheological Behavior of Film-Forming Emulsions}

An AR2000 rheometer (TA Instruments, Leatherhead, UK) fitted with parallel plates (50 mm diameter and $1 \mathrm{~mm}$ gap) was employed to measure the rheological behavior of film forming emulsions. The shear rate was increased linearly from 0 to $100 \mathrm{~s}^{-1}$. A dynamic strain sweep was conducted in a range for angular frequency (omega) of $0.1-100 \mathrm{rad} / \mathrm{s}$ at amplitude (gamma) $=0.1 \%$. The flow rheological properties of emulsion were fitted to the power law equation $(\log$ viscosity $=(n-1) \log$ shear rate $+\log \mathrm{m}$ ) which is applied extensively to describe the rheological behavior of food emulsions [46]. 
The flow behavior index and the consistency coefficient were also calculated from the power law equation, where $\mathrm{n}$ is the flow behavior index, and $\mathrm{m}$ is the consistency coefficient [47].

\subsection{Film Formation}

The films were prepared by casting emulsion, as outlined in Section 3.4, on leveled polytetrafluoroethylene plates $\left(42 \times 42 \mathrm{~cm}^{2}\right)$ and dried using a KBF720 ventilated chamber (Binder, Germany) at $30^{\circ} \mathrm{C}$ and $43 \%$ relative humidity for $18 \mathrm{~h}$.

\subsection{Characterization of Films}

3.8.1. Transparency, Whiteness Index (WI), Swelling Ability, Water Vapor Permeability (WVP) Measurements

The transparency of films was determined by employing Rubilar's method by using the Spark 10M microplate spectrophotometer (Tecan, Switzerland) [48] and calculated by Equation (1). The color of the film was obtained by using a Hunter-Lab colorimeter (Reston, VA, USA) and the L (lightness), $a^{*}$ (redness and greenness), and $b^{*}$ (yellowness and blueness) were recorded. The whiteness index of films was calculated according to Equation (2). The swelling ability of films was measured by immersing the films in water at $25^{\circ} \mathrm{C}$ for $5 \mathrm{~h}$ and then calculated the weight gain (equation (3)) [23]. The water vapor permeability (WVP) of films was tested by using the gravimetric method [49]. Films were placed in measuring cells containing silica gel and deposited in a ventilated chamber at $25^{\circ} \mathrm{C}$ and $75 \%$. The WVP value was calculated according to Equation (4).

$$
\text { Transparency }=\frac{T_{600}}{x}
$$

where $T_{600}$ is the transmittance of light through the film at $600 \mathrm{~nm}$ and $x$ is the film thickness $(\mathrm{mm})$, which was measured by a micrometer with the accuracy of $0.001 \mathrm{~mm}$ (Jiangsu, China).

$$
\begin{gathered}
\text { Whiteness index }=100-\sqrt{(100-L)^{2}+\mathrm{a}^{* 2}+\mathrm{b}^{* 2}} \\
\text { Sweeling }(\%)=\frac{M_{2}-M_{1}}{M_{1}} \times 100
\end{gathered}
$$

where $M_{1}$ is the mass $(\mathrm{g})$ of the initial film before immersion in water and $M_{2}$ is the mass $(\mathrm{g})$ of the film after immersion in water for $5 \mathrm{~h}$.

$$
\mathrm{WVP}=\frac{\Delta \mathrm{m}}{\Delta t \times A}
$$

where $\Delta m$ is the weight gain $(\mathrm{mg})$ of the cups during time $\Delta t(\mathrm{~d})$ and $A$ is the area of exposed film $\left(\mathrm{cm}^{2}\right)$.

\subsubsection{Contact Angle-Sessile Drop Method}

The contact angle of EBEF was tested using an OCA15EC goniometer (Stuttgart, Germany). Deionized $(10 \mu \mathrm{L})$ water was released onto the EBEF, and the image was recorded after $5 \mathrm{~s}$. The contact angle was defined as the angle between the baseline and the tangent to the drop boundary.

\subsubsection{Mechanical Properties}

The tensile strength (TS) and elongation at break (EB) of films were determined using a TA-XT2i texture analyzer (London, UK). The initial distance of separation and cross-head speed was fixed at $50 \mathrm{~mm}$ and $1 \mathrm{~mm} / \mathrm{s}$, respectively. TS was calculated according to Equation (5), and EB was calculated according to Equation (6).

$$
\mathrm{TS}=\frac{\mathrm{F}}{\mathrm{S}}
$$


where $\mathrm{F}$ is the maximum force at break $(\mathrm{Kg})$ and $S$ is the initial transverse section $\left(\mathrm{mm}^{2}\right)$.

$$
\mathrm{EB}(\%)=\frac{L_{2}-L_{1}}{L_{1}} \times 100
$$

where $L_{1}$ is the original length $(\mathrm{mm})$ and $L_{2}$ is the length at break (mm).

\subsubsection{Differential Scanning Calorimetry (DSC)}

The DSC was performed using a thermal analyzer (DSC214 Polyma, Netzsch, Germany). Films (2-4 mg) was heated in an aluminum pan from 25 to $250{ }^{\circ} \mathrm{C}$ at a rate $10{ }^{\circ} \mathrm{C} \mathrm{min}-1$ under nitrogen atmosphere. The data were analyzed with TA Universal Analysis software.

\subsubsection{Thermal Gravimetric Analysis (TG)}

Thermal gravimetric analysis was carried out a Q500 thermal analyzer (TA Instruments, New Castle, USA). Film samples $(7 \mathrm{mg}$ ) were sealed in ceramic pans, and the temperature was raised from 25 to $800{ }^{\circ} \mathrm{C}$ at a heating rate of $10{ }^{\circ} \mathrm{C} \mathrm{min}^{-1}$. The nitrogen was at a constant flow rate of $60 \mathrm{~mL} \mathrm{~min}-1$.

\subsubsection{X-ray}

X-ray diffraction patterns were performed by a Smartlab-3kw X-ray diffractometer (Rigaku, Japan) with $\mathrm{Cu} \mathrm{K} \alpha$ radiation at $40 \mathrm{kV}$ and $30 \mathrm{~mA}$. The scan rate was $10^{\circ} \mathrm{min}^{-1}$ and the patterns were collected in the range of $2 \theta$ from $5^{\circ}$ to $55^{\circ}$.

\subsubsection{Fourier Transform Infrared Spectroscopy (FTIR)}

The Fourier transform infrared spectra of samples were obtained with a FTIR-7600 (Lambda, Australia). Scanning was carried out in the range from 4000 to 400 and $4 \mathrm{~cm}^{-1}$ resolution.

\subsubsection{Scanning Electron Microscopy (SEM)}

The films were sputter-coated with gold-palladium, and the microstructures were observed with MERLIN scanning electron microscope (MERLIN SEM, ZEISS, Germany). The films were fractured by immersing in liquid nitrogen to observe the microstructure of the cross section.

\subsection{Antioxidant and Antimicrobial Activity of Films}

The scavenging activity of ABTS was determined by the method of Yikling et al. [50] with modifications. Films were mixed with ABTS $(7 \mathrm{mM})$ to give a final film concentration of $0.5 \mathrm{mg} / \mathrm{mL}$. After incubation (10 $\mathrm{min}$ ), the sample was centrifuged at $12,000 \times \mathrm{g}, 4^{\circ} \mathrm{C}$ for $2 \mathrm{~min}$. The absorbance values of $200 \mu \mathrm{L}$ supernatant were recorded using a Spark 10M microplate spectrophotometer (Tecan, Switzerland). The solution containing films without free radicals was used as blank.

The films $(1 \mathrm{mg})$ were placed into Luria-Bertani medium $(2 \mathrm{~mL})$ that had been previously seeded with inoculum containing indicator bacteria in the range of $10^{6}-10^{8} \mathrm{CFU} / \mathrm{mL}$, and then they were incubated at $37^{\circ} \mathrm{C}$ for $24 \mathrm{~h}$. The absorbance values of $200 \mu \mathrm{L}$ samples at $600 \mathrm{~nm}$ were measured using a Spark $10 \mathrm{M}$ microplate spectrophotometer at $0,4,8,12$, and $24 \mathrm{~h}$. The medium containing films without bacteria was used as a blank.

\subsection{Essential Oil Release Kinetic from Films}

Release kinetics of the EO from films was performed according to the previous method [44]. The solution of ethanol:water (50:50, v:v) was used as simulant to study the migration. The films $\left(2 \times 2 \mathrm{~cm}^{2}\right)$ were placed inside dialysis bags (12,000 Dalton) and submerged in $30 \mathrm{~mL}$ of simulant. A calibration curve was obtained for EO under study using dilutions of EO with the simulant, and the absorbance was measured at a wavelength of $274 \mathrm{~nm}$ using a Spark $10 \mathrm{M}$ microplate spectrophotometer 
(Tecan, Switzerland). Then, the concentration of EO released in the simulant was determined. Release data were fitted to Weibull (Equation (7)) and Peppas (Equation (8)) models.

$$
\begin{gathered}
\operatorname{Ln}(1-\mathrm{Q})=-\mathrm{a} \cdot t^{b} \\
\mathrm{Q}=K_{P} \cdot t^{n}
\end{gathered}
$$

where $\mathrm{Q}$ is the fraction of $\mathrm{EO}$ released, a and $K_{p}$ are constants, $n$ and $b$ are constants indicative of the release mechanism, and $t$ is time.

\subsection{Statistical Analysis}

All the tests were repeated three times and the data obtained were analyzed by one-way analysis of variance using SPSS Windows version 17.0. Values are expressed as means \pm standard deviation. Duncan's multiple range test was used to identify significant differences $(p<0.05)$ between means.

\section{Conclusions}

The results obtained in this research give some insights on the preparation of edible films using emulsions of PSPI-GA/EO as film-forming solution. It was found that the emulsifying properties of PSPI could be improved after being grafted with GA. The improvement is related to the changes in surface hydrophobicity, secondary structure, and tertiary structure. The droplet size, surface charge, and viscosity of emulsion increased as the EO concentration increased. However, the water vapor barrier property, surface hydrophobicity, mechanical properties, and thermal stability of EBEF were improved as the EO content increased in the range of $1-4 \%$, while it decreased as the EO concentration increased to $6 \%$ due to the formation of a holey microstructure. The release data of $\mathrm{EO}$ from films fitted well to the Peppas model, and the radical scavenging activity of EBEF was significantly affected by the different release patterns due to the variation of $\mathrm{EO}$ concentration.

Supplementary Materials: The following are available online at http://www.mdpi.com/2079-6412/10/8/784/s1, Figure S1: SPME-GC-MS chromatogram of grapefruit essential oil, Table S1: Identification of volatile compounds in grapefruit essential oil.

Author Contributions: Conceptualization, C.L. and F.X.; investigation, J.P.; writing-original draft preparation, C.L.; writing-review and editing, X.X.; project administration, X.X. All authors have read and agreed to the published version of the manuscript.

Funding: This work was supported by Natural Science Foundation of Jiangsu Province (BK20171066) and The Priority Academic Program Development of Jiangsu Higher Education Institutions (035062002002A).

Conflicts of Interest: The authors declare no conflict of interest.

\section{Abbreviations}

The following abbreviations are used in this manuscript:

EBEF emulsion-based edible films

PSPI plum seed protein isolate

GA gum acacia

EO grapefruit essential oil

\section{References}

1. Lacroix, M.; Cooksey, K. 18-Edible films and coatings from animal origin proteins. Innov. Food Packag. 2005, 301-317. [CrossRef]

2. Lin, H.-C.; Wang, B.-J.; Weng, Y.-M. Development and characterization of sodium caseinate edible films cross-linked with genipin. LWT 2020, 118, 108813. [CrossRef]

3. Bourtoom, T. Edible protein films: Properties enhancement. Int. Food Res. J. 2009, 16, 1-9.

4. Debeaufort, F.; Quezada-Gallo, J.A. Lipid hydrophobicity and physical state effects on the properties of bilary edible films. J. Membr. Sci. 2000, 180, 37-46. [CrossRef] 
5. Galus, S.; Kadzińska, J. Food applications of emulsion-based edible films and coatings. Trends Food Sci. Technol. 2015, 45, 273-283. [CrossRef]

6. Fabra, M.J.; Perez-Masia, R.; Talens, P.; Chiralt, A. Influence of the homogenization conditions and lipid self-association on properties of sodium caseinate based films containing oleic and stearic acids. Food Hydrocoll. 2011, 25, 1112-1121. [CrossRef]

7. Akhtar, M.; Dickinson, E. Whey protein-maltodextrin conjugates as emulsifying agents: An alternative to gum arabic. Food Hydrocoll. 2007, 21, 607-616. [CrossRef]

8. Li, C.; Huang, X.; Peng, Q.; Shan, Y.; Xue, F. Physicochemical properties of peanut protein isolate-glucomannan conjugates prepared by ultrasonic treatment. Ultrason. Sonochem. 2014, 21, 1722-1727. [CrossRef]

9. Xue, F.; Li, C.; Zhu, X.; Wang, L.; Pan, S. Comparative studies on the physicochemical properties of soy protein isolate-maltodextrin and soy protein isolate-gum acacia conjugate prepared through Maillard reaction. Food Res. Int. 2013, 51, 490-495. [CrossRef]

10. Xue, F.; Wu, Z.; Tong, J.; Zheng, J.; Li, C. Effect of combination of high-intensity ultrasound treatment and dextran glycosylation on structural and interfacial properties of buckwheat protein isolates. Biosci. Biotechnol. Biochem. 2017, 81, 1891-1898. [CrossRef]

11. Li, C.; Xue, H.; Chen, Z.; Ding, Q.; Wang, X. Comparative studies on the physicochemical properties of peanut protein isolate-polysaccharide conjugates prepared by ultrasonic treatment or classical heating. Food Res. Int. 2014, 57, 1-7. [CrossRef]

12. Li, C.; Zhu, B.; Xue, H.; Chen, Z.; Ding, Q.; Wang, X. Physicochemical Properties of Dry-heated Peanut Protein Isolate Conjugated with Dextran or Gum Arabic. J. Am. Oil Chem. Soc. 2013, 90, 1801-1807. [CrossRef]

13. Li, C.; Zhu, W.; Xue, H.; Chen, Z.; Chen, Y.; Wang, X. Physical and structural properties of peanut protein isolate-gum Arabic films prepared by various glycation time. Food Hydrocoll. 2015, 43, 322-328. [CrossRef]

14. Zhou, C.; Qian, L.; Ma, H.; Yu, X.; Zhang, Y.; Qu, W.; Zhang, X.; Xia, W. Enhancement of amygdalin activated with $\beta$-D-glucosidase on HepG2 cells proliferation and apoptosis. Carbohydr. Polym. 2012, 90, 516. [CrossRef] [PubMed]

15. Brahmi, F.; Abdenour, A.; Bruno, M.; Silvia, P.; Alessandra, P.; Danilo, F.; Drifa, Y.-G.; Fahmi, E.M.; Khodir, M.; Mohamed, C. Chemical composition and in vitro antimicrobial, insecticidal and antioxidant activities of the essential oils of Mentha pulegium L. and Mentha rotundifolia (L.) Huds growing in Algeria. Ind. Crops Prod. 2016, 88, 96-105. [CrossRef]

16. Cristóbal-Luna, J.M.; Álvarez-González, I.; Madrigal-Bujaidar, E.; Chamorro-Cevallos, G. Grapefruit and its biomedical, antigenotoxic and chemopreventive properties. Food Chem. Toxicol. 2017, 112, $224-234$. [CrossRef]

17. Ribeiro-Santos, R.; Andrade, M.; de Melo, N.R.; Sanches-Silva, A. Use of essential oils in active food packaging: Recent advances and future trends. Trends Food Sci. Technol. 2017, 61, 132-140. [CrossRef]

18. Li, C.; Wang, J.; Shi, J.; Huang, X.; Peng, Q.; Xue, F. Encapsulation of tomato oleoresin using soy protein isolate-gum aracia conjugates as emulsifier and coating materials. Food Hydrocoll. 2015, 45, 301-308. [CrossRef]

19. Xue, F.; Gu, Y.; Wang, Y.; Li, C.; Adhikari, B. Encapsulation of essential oil in emulsion based edible films prepared by soy protein isolate-gum acacia conjugates. Food Hydrocoll. 2019, 96, 178-189. [CrossRef]

20. Kato, A. Industrial Applications of Maillard-Type Protein-Polysaccharide Conjugates. Food Sci. Technol. Res. 2002, 8, 193-199. [CrossRef]

21. Atarés, L.; De Jesús, C.; Talens, P.; Chiralt, A. Characterization of SPI-based edible films incorporated with cinnamon or ginger essential oils. J. Food Eng. 2010, 99, 384-391. [CrossRef]

22. Atarés, L.; Bonilla, J.; Chiralt, A. Characterization of sodium caseinate-based edible films incorporated with cinnamon or ginger essential oils. J. Food Eng. 2010, 100, 678-687. [CrossRef]

23. Hopkins, E.J.; Chang, C.; Lam, R.S.H.; Nickerson, M.T. Effects of flaxseed oil concentration on the performance of a soy protein isolate-based emulsion-type film. Food Res. Int. 2015, 67, 418-425. [CrossRef]

24. Ma, W.; Tang, C.H.; Yin, S.W.; Yang, X.Q.; Wang, Q.; Liu, F.; Wei, Z.H. Characterization of gelatin-based edible films incorporated with olive oil. Food Res. Int. 2012, 49, 572-579. [CrossRef]

25. Kokoszka, S.; Debeaufort, F.; Lenart, A.; Voilley, A. Liquid and vapour water transfer through whey protein/lipid emulsion films. J. Sci. Food Agric. 2010, 90, 1673-1680. [CrossRef]

26. Xu, X.; Liu, W.; Zhang, L. Rheological behavior of Aeromonas gum in aqueous solutions. Food Hydrocoll. 2006, 20, 723-729. [CrossRef] 
27. Peressini, D.; Bravin, B.; Lapasin, R.; Rizzotti, C.; Sensidoni, A. Starch-methylcellulose based edible films: Rheological properties of film-forming dispersions. J. Food Eng. 2003, 59, 25-32. [CrossRef]

28. Acevedo-Fani, A.; Salvia-Trujillo, L.; Martín-Belloso, O. Edible films from essential-oil-loaded nanoemulsions: Physicochemical characterization and antimicrobial properties. Food Hydrocoll. 2015, 47, 168-177. [CrossRef]

29. Arzeni, C.; Martínez, K.; Zema, P.; Arias, A.; Pérez, O.E.; Pilosof, A.M.R. Comparative study of high intensity ultrasound effects on food proteins functionality. J. Food Eng. 2012, 108, 463-472. [CrossRef]

30. Sun, W.W.; Yu, S.J.; Yang, X.Q.; Wang, J.M.; Zhang, J.B.; Zhang, Y.; Zheng, E.L. Study on the rheological properties of heat-induced whey protein isolate-dextran conjugate gel. Food Res. Int. 2011, 44, 3259-3263. [CrossRef]

31. Binsi, P.K.; Ravishankar, C.N.; Gopal, T.K.S. Development and Characterization of an Edible Composite Film Based on Chitosan and Virgin Coconut Oil with Improved Moisture Sorption Properties. J. Food Sci. 2013, 78, E526-E534. [CrossRef] [PubMed]

32. Fabra, M.J.; Talens, P.; Chiralt, A. Tensile properties and water vapor permeability of sodium caseinate films containing oleic acid-beeswax mixtures. J. Food Eng. 2008, 85, 393-400. [CrossRef]

33. Han, J.H.; Seo, G.H.; Park, I.M.; Kim, G.N.; Lee, D.S. Physical and Mechanical Properties of Pea Starch Edible Films Containing Beeswax Emulsions. J. Food Sci. 2010, 71, E290-E296. [CrossRef]

34. Valenzuela, C.; Abugoch, L.; Tapia, C. Quinoa protein-chitosan-sunflower oil edible film: Mechanical, barrier and structural properties. LWT Food Sci. Technol. 2013, 50, 531-537. [CrossRef]

35. Wang, K.; Wu, K.; Xiao, M.; Kuang, Y.; Corke, H.; Ni, X.; Jiang, F. Structural characterization and properties of konjac glucomannan and zein blend films. Int. J. Biol. Macromol. 2017, 105. [CrossRef] [PubMed]

36. Su, J.F.; Huang, Z.; Yuan, X.Y.; Wang, X.Y.; Li, M. Structure and properties of carboxymethyl cellulose/soy protein isolate blend edible films crosslinked by Maillard reactions. Carbohydr. Polym. 2010, 79, 145-153. [CrossRef]

37. Gheribi, R.; Puchot, L.; Verge, P.; Jaoued-Grayaa, N.; Mezni, M.; Habibi, Y.; Khwaldia, K. Development of Plasticized Edible Films from Opuntia ficus-indica Mucilage: A Comparative Study of Various Polyol Plasticizers. Carbohydr. Polym. 2018, 190, 204-211. [CrossRef]

38. Dou, L.; Li, B.; Zhang, K.; Chu, X.; Hou, H. Physical properties and antioxidant activity of gelatin-sodium alginate edible films with tea polyphenol. Int. J. Biol. Macromol. 2018, 118, 1377-1383. [CrossRef]

39. Norajit, K.; Kim, K.M.; Ryu, G.H. Comparative studies on the characterization and antioxidant properties of biodegradable alginate films containing ginseng extract. J. Food Eng. 2010, 98, 377-384. [CrossRef]

40. Sun, H.; Li, S.; Chen, S.; Wang, C.; Liu, D.; Li, X. Antibacterial and antioxidant activities of sodium starch octenylsuccinate-based Pickering emulsion films incorporated with cinnamon essential oil. Int. J. Biol. Macromol. 2020, 159, 696-703. [CrossRef]

41. Chu, Y.; Cheng, W.; Feng, X.; Gao, C.; Wu, D.; Meng, L.; Zhang, Y.; Tang, X. Fabrication, structure and properties of pullulan-based active films incorporated with ultrasound-assisted cinnamon essential oil nanoemulsions. Food Packag. Shelf Life 2020, 25, 100547. [CrossRef]

42. De Souza, A.G.; dos Santos, N.M.A.; da Silva Torin, R.F.; dos Santos Rosa, D. Synergic antimicrobial properties of Carvacrol essential oil and montmorillonite in biodegradable starch films. Int. J. Biol. Macromol. 2020. [CrossRef] [PubMed]

43. Bustos, C.R.O.; Alberti, R.F.O.; Matiacevich, S.B. Edible antimicrobial films based on microencapsulated lemongrass oil. J. Food Sci. Technol. 2016, 53, 832. [CrossRef] [PubMed]

44. Lidia Herrera, M.; Bustos, R.O.; Matiacevich, S.B.; Alarcón-Moyano, J.K. Alginate edible films containing microencapsulated lemongrass oil or citral: Effect of encapsulating agent and storage time on physical and antimicrobial properties. J. Food Sci. Technol. 2017, 54, 2878-2889.

45. Xue, F.; Zhu, C.; Liu, F.; Wang, S.; Liu, H.; Li, C. Effects of high-intensity ultrasound treatment on functional properties of plum (Pruni domesticae semen) seed protein isolate. J. Sci. food Agric. 2018, 98, 5690-5699. [CrossRef]

46. Silva, E.K.; Gomes, M.T.M.S.; Hubinger, M.D.; Cunha, R.L.; Meireles, M.A.A. Ultrasound-assisted formation of annatto seed oil emulsions stabilized by biopolymers. Food Hydrocoll. 2015, 47, 1-13. [CrossRef]

47. Hu, H.; Wu, J.; Li-Chan, E.C.Y.; Zhu, L.; Zhang, F.; Xu, X.; Fan, G.; Wang, L.; Huang, X.; Pan, S. Effects of ultrasound on structural and physical properties of soy;protein isolate (SPI) dispersions. Food Hydrocoll. 2013, 30, 647-655. [CrossRef] 
48. Rubilar, J.F.; Zúñiga, R.N.; Osorio, F.; Pedreschi, F. Physical properties of emulsion-based hydroxypropyl methylcellulose/whey protein isolate (HPMC/WPI) edible films. Carbohydr. Polym. 2015, 123, 27-38. [CrossRef]

49. Wu, C.; Peng, S.; Wen, C.; Wang, X.; Fan, L.; Deng, R.; Pang, J. Structural characterization and properties of konjac glucomannan/curdlan blend films. Carbohydr. Polym. 2012, 89, 497-503. [CrossRef]

50. Yikling, C.; Jookheng, G.; Yauyan, L. Assessment of in vitro antioxidant capacity and polyphenolic composition of selected medicinal herbs from Leguminosae family in Peninsular Malaysia. Food Chem. 2009, $116,13-18$.

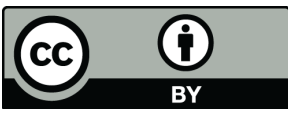

(C) 2020 by the authors. Licensee MDPI, Basel, Switzerland. This article is an open access article distributed under the terms and conditions of the Creative Commons Attribution (CC BY) license (http://creativecommons.org/licenses/by/4.0/). 